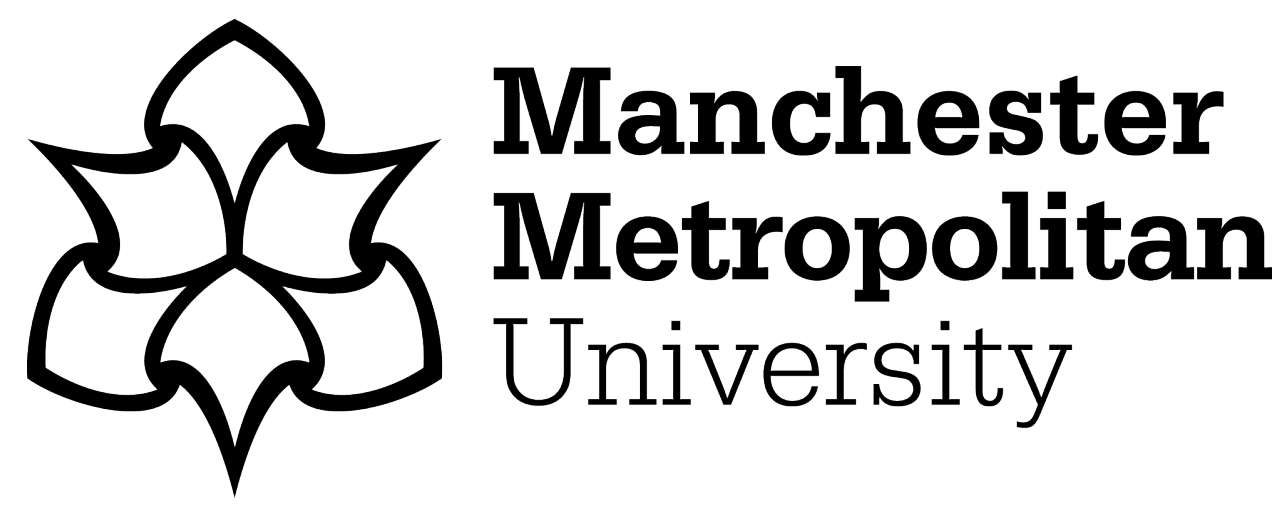

Shi, Xiangru, Liskiewicz, Tomasz W ORCID logoORCID: https://orcid.org/0000-0002-0866-814X, Beake, Ben D, Sun, Zhengming and Chen, Jian (2019) Fretting wear behavior of graphite-like carbon films with bias-graded deposition. Applied Surface Science, 494. pp. 929-940. ISSN 0169-4332

Downloaded from: https://e-space.mmu.ac.uk/624208/

Version: Accepted Version

Publisher: Elsevier

DOI: https://doi.org/10.1016/j.apsusc.2019.07.265

Please cite the published version 


\title{
Fretting wear behavior of graphite-like carbon films with bias-graded deposition
}

Xiangru Shi ${ }^{\mathrm{a}, \mathrm{b}}$, Tomasz W. Liskiewicz ${ }^{\mathrm{b}}$, Ben D. Beake ${ }^{\mathrm{c}}$, Zhengming Sun ${ }^{\mathrm{a}}$, Jian Chen $^{\mathrm{a}^{*}}$

a. School of Materials Science and Engineering, Jiangsu Key Laboratory for Advanced Metallic Materials, Southeast University, Nanjing 211189, China

b. Institute of Functional Surface, School of Mechanical Engineering, University of Leeds, Leeds LS29JT, United Kingdom

c. Micro Materials Ltd., Willow House, Yale Business Village, Ellice Way, Wrexham, LL13 7YL, United Kingdom

* Corresponding author. Tel: +86 25 52090688. E-mail address: j.chen@seu.edu.cn

\begin{abstract}
Although graphite-like carbon (GLC) films have been used to protect the engineering components due to their high mechanical properties and low friction coefficients, the poor interfacial bonding strength and high internal stress can lead their rapid failure. In this study, the bias-gradient (30-120V) as well as the usual constant bias protocols (30, 60 and 120V) has been adopted to deposit the GLC films on 316L stainless steel and silicon using unbalanced magnetron sputtering technology. Based upon the microstructure and composition analysis by SEM, AFM, XRD, Raman and XPS, the $\mathrm{sp}^{3}$ content and compactness of the films are increased with the increase of the deposition bias. Compared to the film at the constant bias of $120 \mathrm{~V}$, the bias-graded film has a comparable hardness but superior adhesive strength. Detailed fretting wear testing under ambient air and dry $\mathrm{N}_{2}$ atmospheres against $25 \mathrm{~mm}$ diameter $\mathrm{Si}_{3} \mathrm{~N}_{4}$ ball has been carried out. The friction curves disclosed a three-stage evolution feature: the surface working area, the interlayer transition area and the coating failure area. The bias-graded film displayed the lowest friction coefficient and the longest fatigue life. Further the fretting mechanisms at different stages have been elaborated in terms of the chemical composition, microstructure and mechanical properties.
\end{abstract}

Keywords: graphite-like carbon films, bias-graded deposition, microstructure, fretting wear, failure mechanism 


\section{Introduction}

Fretting wear is generated by the relatively oscillatory tangential movement of small amplitude between two contacting surfaces with cyclic loading, which can cause subsequently catastrophic failure in various mechanical components [1.2]. For instance, metallic materials such as 316L stainless steels have been widely used as in automotive, aerospace, biomedical and other industries owing to their excellent corrosion resistance and favourable biocompatibility [3.4]. However, the low hardness and tribological properties can cause poor fretting wear resistance, and thus restrict their applications [3].

Amorphous carbon (a-C) films, mainly consisting of $\mathrm{sp}^{3}$ and $\mathrm{sp}^{2}$ hybridized carbon atoms, possess high hardness and low friction coefficient $(\mathrm{CoF})$, and have been widely used to protect the surface of components [5-8]. According to the contents of $\mathrm{sp}^{3}$ and $\mathrm{sp}^{2}$ bonds, these films can be termed as DLC (diamond-like carbon, dominated by $\mathrm{sp}^{3}$ ) and GLC (graphite-like carbon, dominated by $\mathrm{sp}^{2}$ ) [9-11]. Currently, several studies have reported that the DLC films can effectively improve the fretting wear and fracture resistance of the component surface. Amanov et al. [2] deposited Cr-doped and non-doped DLC films on Ti-6al-4V by unbalanced magnetron sputtering. It was reported that both DLC films exhibited lower friction coefficients and wear rates than the uncoated specimen, and also the non-doped DLC showed improved fatigue life than the doped one. Ding et al. [12] reported that the harder and stiffer DLC on smooth substrate presented better fretting resistance, and the increase in the normal force and displacement accelerated the film failure. Tobi et al. [13] considered the lower CoF of the deposited DLC was the main factor to the increased fretting fatigue life of the coated specimen by reducing the cyclic shear load experienced and its local contact edge stresses. The wear resistance is mainly attributed to the high hardness which eliminates the adhesive wear and debris transfer in the fretting regime [14].

However, the protective effects of the a-C films for metallic materials are strongly affected by their adhesion strength due to the high intrinsic stress in the films [5.15.16]. Currently, many methods have been utilized to lower the internal stress and improve the adhesion strength, including modulation of composition by doping of metal and non-metal elements [15], structural design with graded interlayer [17] and multilayer structure [18]. As the film microstructure is strongly influenced by the deposition bias [6.19-21], the bias-graded deposition by increasing the ion energy stepwise has also been proposed to be an effective solution to release the internal 
stress, with that the strong ion bombardment produces a dense and hard film surface, and the modification of the interface regions between the substrate and the graded layers ensures a good adhesion [22.23]. For instance, Zhang et al. [24] produced the bias-graded DLC films $(-20 \mathrm{~V}$ to $-150 \mathrm{~V})$ via DC magnetron sputtering with a comparable hardness of $25 \mathrm{GPa}$ to that deposited with a constant bias of $-150 \mathrm{~V}$, but significantly enhanced toughness and adhesion strength. Cai et al. [25] deposited a Ti-containing a-C gradient composite film using a closed field unbalanced magnetron sputtering with bias-graded voltage from $-20 \mathrm{~V}$ to $-150 \mathrm{~V}$. Besides the improved toughness and adhesion strength, lower friction coefficient and wear rate were also found in ambient air and Hank's solution.

However, within the knowledge of the authors, there are few literatures focusing on the fretting mechanisms of GLC films, and even no reports on the effects of interfacial strength by altering the bias in GLC on the fretting behaviour. It is thus meaningful to conduct systematic research on the fretting wear of bias-graded GLC film, which is beneficial for the design of films for challenging applications. Hence, two types of GLC films with constant and gradient bias voltage were deposited using closed filed unbalanced magnetron sputtering. The microstructure and mechanical properties were comparatively investigated as a function of substrate bias. The fretting wear and fatigue behaviour were conducted on a ball-on-flat fretting configuration under ambient air and dry $\mathrm{N}_{2}$ atmosphere. The wear process and failure mechanism were explored by the SEM images of wear scar and profile analysis. The relationship between the films microstructure, mechanical and tribological properties is also discussed.

\section{Experimental details}

\subsection{Film deposition}

The closed field unbalanced magnetron sputtering system (UDP-650/4, Teer Coating Ltd., UK) was used to prepare the GLC films, equipped with two Ti targets (purity 99.99\%) and two graphite targets (purity 99.99\%) opposing each other. A three-axis substrate rotation worktable was employed during deposition to produce uniform films. The substrate used for deposition were silicon (100) wafers and mirror-polished $316 \mathrm{~L}$ stainless steel coupons with size of $20 \times 20 \times 0.5 \mathrm{~mm}$, both of which were cleaned ultrasonically in acetone and ethanol for $20 \mathrm{~min}$ in succession, and then blow-dried by nitrogen gas. Coated silicon wafers were only used to characterize microstructure and chemical composition, and the mechanical and tribological tests were conducted on coated stainless steel samples.

Prior to deposition, the base pressure of the chamber was adjusted to $0.3 \mathrm{~Pa}$, when the 
argon gas with a constant flow of $25 \mathrm{sccm}$ was introduced. The surface oxides layer on the substrate was removed by sputter-cleaning with $\mathrm{Ar}^{+}$bombardment at a negative bias of $500 \mathrm{~V}$, following target-cleaning for $5 \mathrm{~min}$ at $120 \mathrm{~V}$. After that, a Ti sub-layer was deposited for $15 \mathrm{~min}$ at $60 \mathrm{~V}$ to improve the interfacial bonding. Subsequently, the Ti target currents was decreased gradually to $0.8 \mathrm{~A}$ within $45 \mathrm{~min}$, while the graphite target currents were increased gradually to $3 \mathrm{~A}$, in order to generate a functional Ti-C gradient layer. Finally, the uniform Ti-containing GLC layer was deposited for $1 \mathrm{~h}$ with different constant negative bias voltage of $30 \mathrm{~V}, 60 \mathrm{~V}$ and $120 \mathrm{~V}$, respectively. Different to the films deposited at constant bias voltage, the bias-graded film was prepared at a continuously increased substrate bias from $30 \mathrm{~V}$ to $120 \mathrm{~V}$ at a rate of $5 \mathrm{~V}$ for every $5 \mathrm{~min}$. The detailed deposition parameters are summarised in Table 1.

Table 1. Deposition parameters for GLC films.

\begin{tabular}{ccccccc}
\hline Parameter & $\begin{array}{c}\text { Substrate } \\
\text { clean }\end{array}$ & $\begin{array}{c}\text { Target } \\
\text { clean }\end{array}$ & $\begin{array}{c}\text { Adhesive } \\
\text { layer }\end{array}$ & $\begin{array}{c}\text { Transition } \\
\text { layer }\end{array}$ & $\begin{array}{c}\text { GLC } \\
\text { layer }\end{array}$ & $\begin{array}{c}\text { Sample } \\
\text { name }\end{array}$ \\
\hline Time (min) & 30 & 5 & 15 & 45 & 60 & \\
& & & & & 30 & CB1 \\
Negative bias (V) & 500 & 120 & 60 & 60 & $\begin{array}{c}120 \\
\text { CB2 }\end{array}$ & CB3 \\
$\begin{array}{c}\text { Ti target current } \\
\text { (A) }\end{array}$ & 0.5 & 2 & 3 & $3-0.8$ & 0.8 & \\
$\begin{array}{c}\text { C target current } \\
\text { (A) }\end{array}$ & 0 & 0 & 0.3 & $0.3-3$ & 3 & \\
\hline
\end{tabular}

\subsection{General characterisation}

The surface and cross-sectional morphologies of the GLC films were examined using scanning electron microscopy (SEM) (XL-30, FEI Co., USA) at $20.0 \mathrm{KV}$. Their thickness was estimated from the SEM cross-sectional images. The surface roughness was determined by atomic force microscopy (AFM) (Bruker Co., German). The amorphous structure was investigated using X-ray diffraction (XRD) carried out by an $\mathrm{X}$-ray spectrometer (D8-Discover, Bruker Co., German) with $\mathrm{Cu} \mathrm{K \alpha}$ radiation $(\lambda=1.5405 \AA)$. Raman spectra in the range of $1000-2000 \mathrm{~cm}^{-1}$ were obtained by an inVia-reflex Raman spectrometer (Renishaw Co., UK) using an $\mathrm{Ar}^{+}$laser of $532 \mathrm{~nm}$. The chemical composition and bond structure were also characterized by a versatile X-ray photoelectron spectroscopy (XPS) (EnviroESCA, Leeds Electron Microscopy and Spectroscopy Centre) with Al Ka irradiation. In order to avoid the influence of surface contamination, each sample was cleaned by $\mathrm{Ar}^{+}$at a beam voltage at $2 \mathrm{kV}$ for $10 \mathrm{~min}$. 


\subsection{Mechanical testing}

The hardness $(H)$ and elastic modulus $(E)$ of the films were determined using a calibrated nanoindentation system (NanoTest Vantage, Micro Materials Limited, UK) with a Berkovich diamond indenter using the Oliver-Pharr method [26]. In order to eliminate the substrate effect, the maximum load of $2 \mathrm{mN}$ was applied to control that the indentation depth is less than $10 \%$ of the film thickness. Fifteen repeated indentations were carried out on different areas for each sample. The adhesion strength of the films to the stainless steel substrate was measured by the conventional scratch test system (WS-2002 equipped with an acoustic emission detector) and Rockwell indentation system (HR-150A), respectively. A diamond pyramidal tip was driven to scratch the film surface at a load rate of $60 \mathrm{~N} / \mathrm{min}$ to the peak load of $60 \mathrm{~N}$ with the maximum trace length of $4 \mathrm{~mm}$. The Rockwell indentation testing was set by keeping the indenter (cone angle $120^{\circ}$, tip radius $0.2 \mathrm{~mm}$ ) in contact with the sample at a maximum load of $150 \mathrm{kgf}$ for $40 \mathrm{~s}$, and then the indentation morphologies were observed for a qualitative evaluation. The curvature radius of the silicon substrates before and after the deposition of GLC films were measured by Talysurf surface profilometer, and the internal stress was calculated by the Stoney's equation [25]:

$\sigma=\frac{E_{S}}{6\left(1-v_{s}\right)}\left(\frac{t_{s}^{2}}{t_{f}}\right)\left(\frac{1}{R_{2}}-\frac{1}{R_{1}}\right)$

Equation (1)

where $\sigma$ is the internal stress, $E_{s}, v_{s}$, and $t_{s}$ is the Young's modulus, Poisson's ratio, and the thickness of silicon substrate, respectively, $t_{f}$ is the thickness of GLC films, $R_{1}$ and $R_{2}$ is the curvature radius of the substrate before and after deposition, respectively.

\subsection{Fretting wear testing}

The fretting wear tests were conducted out using a homemade ball-on-flat fretting configuration [27.28]. As shown by the schematic diagram in Figure 1a, a dedicated electrodynamic shaker was used to generate tangential displacement of the $\mathrm{Si}_{3} \mathrm{~N}_{4}$ ceramic ball with a diameter of $25.4 \mathrm{~mm}$ on the surface of GLC films under a constant normal load of $40 \mathrm{~N}$, which generate a maximum Hertz contact pressure of about 0.8 $\mathrm{GPa}$. The reason to use the $\mathrm{Si}_{3} \mathrm{~N}_{4}$ mating ball is due to the high hardness and excellent wear resistance. All experiments were set in both ambient air and dry $\mathrm{N}_{2}$ atmosphere at $5 \mathrm{~Hz}$ frequency and $\pm 100 \mu \mathrm{m}$ displacement amplitude. Tangential force (Q) and relative displacement $(\delta)$ were recorded continuously by the installed sensors, respectively, which allowed to characterise every fretting cycles with a characteristic fretting loop (Figure 1b). The tests were terminated manually when the calculated friction coefficient increased abruptly to the value of the stainless steel substrate $(\sim 0.9)$. After the testing, the surface damage was examined by white light interferometer (NPFLEX 3D, Bruker) and scanning electron microscopy. 
(a)

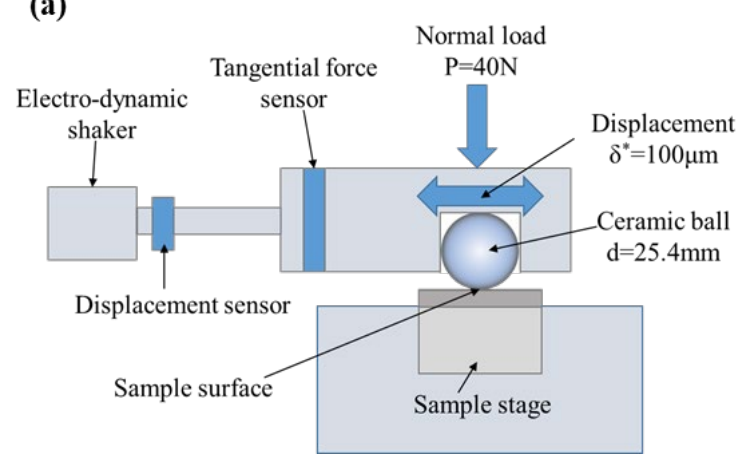

(b)

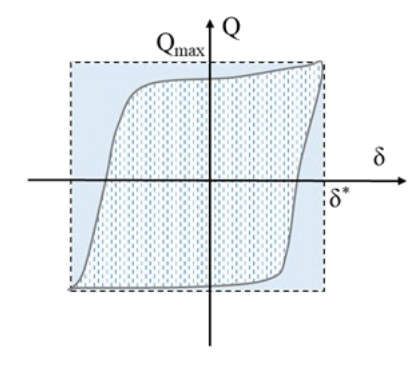

Figure 1. (a) Schematic diagram of fretting test device, (b) typical fretting loop.

\section{Results and discussion}

\subsection{Microstructure and composition of GLC films}

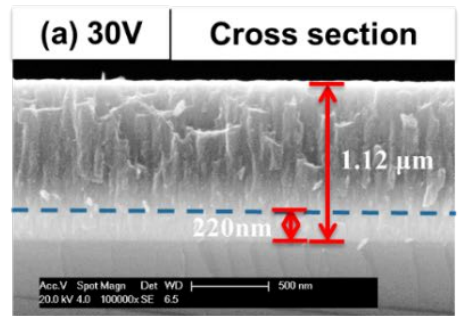

(b) $60 \mathrm{~V}$

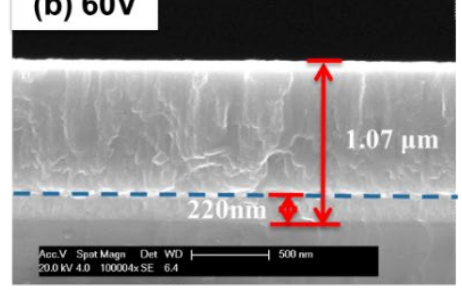

(c) $120 \mathrm{~V}$

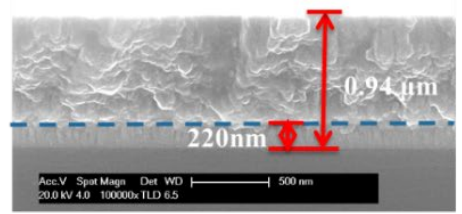

(d) $30-120 \mathrm{~V}$

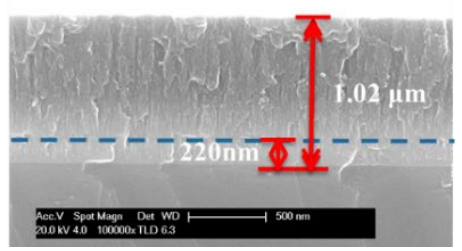

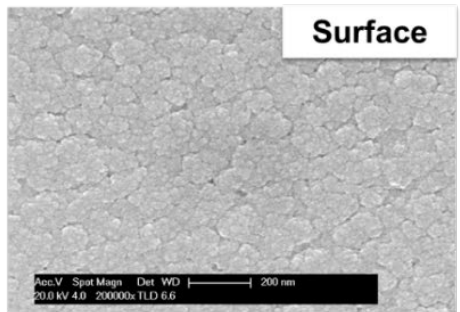
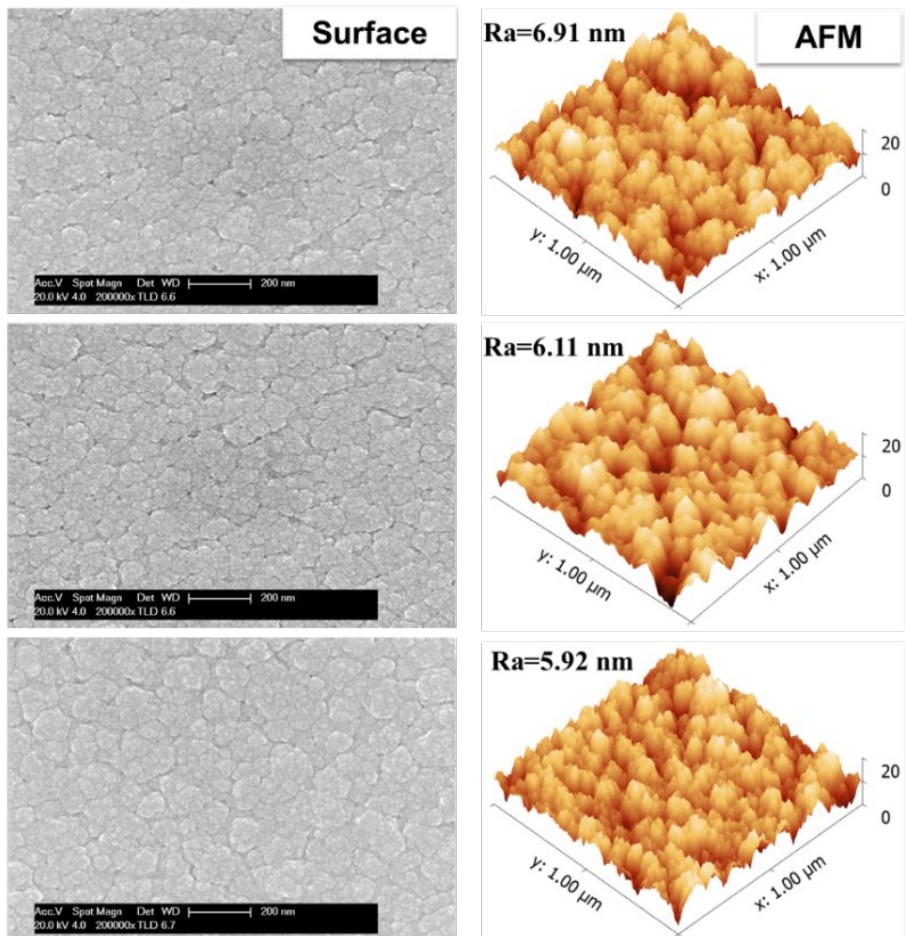

$R a=6.03 \mathrm{~nm}$

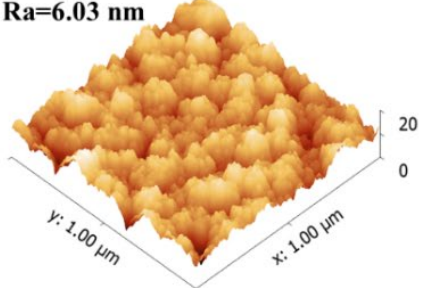

Figure 2. SEM images for cross-sectional and surface morphologies and corresponding AFM surface images of GLC films deposited by different negative bias: (a) $30 \mathrm{~V}$, (b) $60 \mathrm{~V}$, (c) $120 \mathrm{~V}$, (d) $30-120 \mathrm{~V}$.

The surface and cross-sectional morphologies of the GLC films deposited with 
different negative bias voltage were observed using SEM shown in Figure 2. It can be seen in the left cross-sectional images of Figure 2a-c that the thickness of the GLC films decreases gradually with the increase of constant bias. A loose columnar structure can be clearly observed for Sample CB1 with the lowest negative bias of $30 \mathrm{~V}$, while the $\mathrm{CB} 2$ and $\mathrm{CB} 3$ deposited with higher negative bias show more uniform and dense microstructure. The surface morphologies in the middle pictures reveal double structures, which is composed of some larger packs aggregated by the fine grains. The 3D surface morphology of the GLC films was also obtained using the AFM in the right picture of Figure 2. The defects on the surface of the films reduce gradually, while the compactness increases with the increase of the constant bias. The measured average surface roughness $\left(R_{\mathrm{a}}\right)$ of the GLC films was 6.91, 6.11 and 5.92nm for constant bias films of CB1, CB2 and CB3, respectively. For the bias-graded GLC film of $\mathrm{BB} 1$, the thickness and surface roughness is $1.02 \mu \mathrm{m}$ and $6.03 \mathrm{~nm}$, respectively, slightly higher than CB3 deposited at $120 \mathrm{~V}$.

A broad peak at the range of $10^{\circ}$ to $30^{\circ}$ can be observed in the XRD patterns of the GLC films (Figure 3a), revealing the amorphous structure of all the films [21]. Raman spectra in Figure 3b show two typical characteristic peaks termed G peak at $\sim 1550 \mathrm{~cm}^{-1}$ and D peak at $\sim 1350 \mathrm{~cm}^{-1}$ by Gaussian deconvolution. The former is related to the stretching vibration of any pairs of $\mathrm{sp}^{2}$ sites in both rings and chains, while the latter is the breathing mode of those $\mathrm{sp}^{2}$ sites only in aromatic disorder rings [7.17.22]. With the increase of constant negative bias, the intensity ratio of $\mathrm{D}$ peak and $\mathrm{G}$ peak (ID/IG) in Figure 3c decreases, and also the $\mathrm{G}$ peak position shifts to the low wavelength and the full width at half maximum of G peak (FWHM) increases as shown in Figure 3d. These findings suggest that the higher $\mathrm{sp}^{3}$ content for the film deposited at higher constant bias. In comparison with the $\mathrm{CB}$ series films, the BB1 with the graded-bias also shows high $\mathrm{sp}^{3}$ content, but slightly less than that for the CB3. 

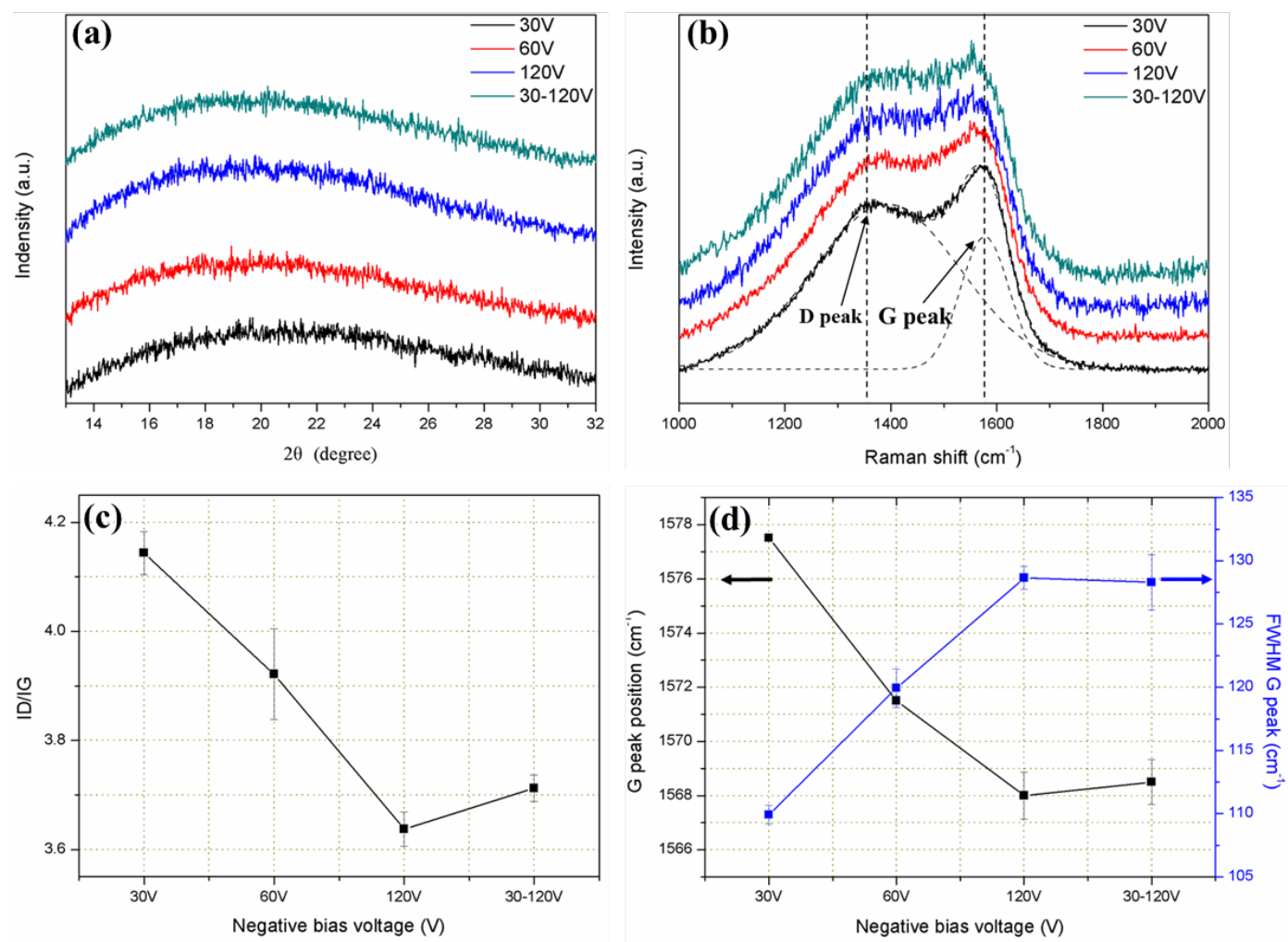

Figure 3. (a) XRD images, (b) Raman spectra of GLC films deposited at different negative bias, (c) ID/IG, (d) G peak position and the full width at half maximum of $\mathrm{G}$ peak calculated by fitting the Raman curves.

The detailed content of $\mathrm{sp}^{3}$ carbon atoms was further investigated by XPS analysis. As shown in Figure 4a, the typical C1s peak of amorphous carbon is fitted into three different sub-peaks of the $\mathrm{C}=\mathrm{C} \mathrm{sp}{ }^{2}$ peak $(284.6 \mathrm{eV}), \mathrm{C}-\mathrm{C} \mathrm{sp}{ }^{3}$ peak $(285.1 \mathrm{eV})$, as well as the C-O peak at $286.8 \mathrm{eV}$ [9-11]. There are few carbon-oxygen bonds in the films, which may be attributed to residual oxygen in the chamber. Figure $4 \mathbf{b}$ shows the calculated fraction of the $\mathrm{sp}^{2}$ bond and the $\mathrm{sp}^{3}$ bond of the GLC films. It can be see that the $\mathrm{sp}^{2}$ carbon atoms are dominant in the structure of the GLC films, which decreases from $80.1 \%$ to $52.4 \%$ as the constant negative bias increases from $30 \mathrm{~V}$ to $120 \mathrm{~V}$. Besides, the $\mathrm{sp}^{2}$ content for the bias-graded film is a little higher than the film deposited at constant bias of $120 \mathrm{~V}$. These results are in consistent with the Raman analysis [9]. 

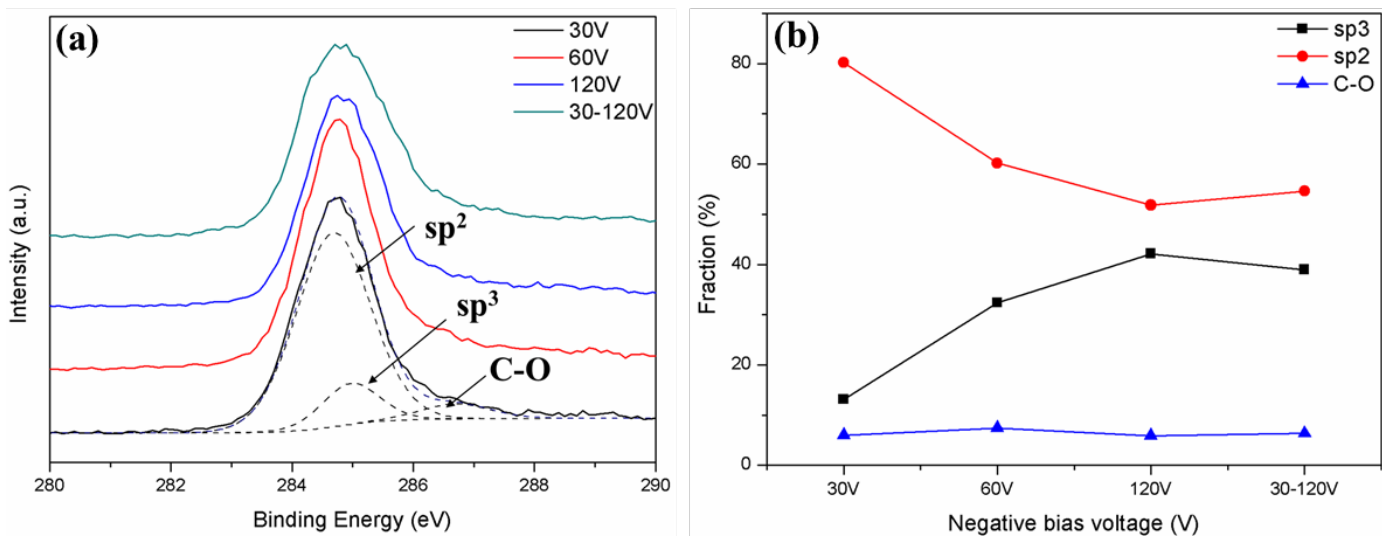

Figure 4. (a) Measured C1s peaks by XPS and fitting curves of the GLC films deposited at different negative bias voltage, (b) the content of $\mathrm{sp}^{2}, \mathrm{sp}^{3}$ carbon atoms and the bond of $\mathrm{C}-\mathrm{O}$.

The evolution of bonds and microstructure with the bias can be attributed to the altered ion energy modulated by the bias [10.11.20.29]. According to the subplantation model [5.30.31], the impinging species with an energy beyond a critical value will have a high probability to penetrate into the subsurface interstitial site of bombarded sample, resulting in the densification of the film and transformation of $\mathrm{sp}^{2}$ carbon atoms to $\mathrm{sp}^{3}$ bond. On the other hand, when the ion energy is less than the penetration threshold, the incoming carbon ions just diffuse in surface layers and remain in their lowest energy state of $\mathrm{sp}^{2}$. Indeed, the ion energy is relevant with the applied bias voltage during the deposition. For CB1 with the lowest bias voltage of $30 \mathrm{~V}$, the carbon ions with the lowest kinetic energy may be mainly trapped on the surface, leading to the more $\mathrm{sp}^{2}$ atoms with a loose and rough microstructure. When the negative bias increase to the highest value of $120 \mathrm{~V}$ (CB3), the energy of carbon ions is high enough to penetrate into the interior of the structure and dissipate into the volume nearby, resulting in the formation of dense and smooth microstructure with more $\mathrm{sp}^{3}$ atoms. Furthermore, the enhanced re-sputtering or etching effect on the fresh surface of the as-deposited film is also a non-negligible factor to the decreased film thickness from 1.12 to $0.94 \mu \mathrm{m}$ when the constant bias increases from $30 \mathrm{~V}$ to $120 \mathrm{~V}$ [32].

For the bias-graded film of BB1, although the $\mathrm{sp}^{3}$ content was lowest at the initial stage, especially nearby the interface due to the low bias, the final high bias of $120 \mathrm{~V}$ can also densify the carbon films and increase the number of $\mathrm{sp}^{3}$ atoms. In turn, the average content of $\mathrm{sp}^{3}$ in $\mathrm{BB} 1$ is only slightly lower than that with the constant high bias of $120 \mathrm{~V}$. Similar observation has been also reported by analysing the composition of bias-graded DLC films at different etching depth using XPS [25]. 


\subsection{Mechanical properties of GLC films}

Figure 5a shows the calculated internal stress of GLC films. It can be seen that the compressive stress increases with the increase of the constant bias, and reaches a maximum value of $1.05 \mathrm{GPa}$ for $\mathrm{CB} 3$ at constant bias of $120 \mathrm{~V}$, followed by an apparent decrease to about $0.76 \mathrm{GPa}$ for the bias-graded BB1 film. The relatively low value may be attributed to the deposition of $\mathrm{Ti}$ adhesive layer and the Ti-C gradient layer. Understandably, the compressive internal stress is generated by the bombardment of energetic particles [18.21]. As described above, the ion energy is too weak to penetrate into the subsurface of the film at a low bias, resulting in the loose microstructure and low internal stress. When the negative bias increases to $120 \mathrm{~V}$, the high energy of bombarding particles could get rise to the densification of the film and produce higher residual stress in the film. The low value for bias-graded GLC film could be attributed to the gradual variation of the $\mathrm{sp}^{3} / \mathrm{sp}^{2}$ ratio induced by the gradually increased negative bias [25].
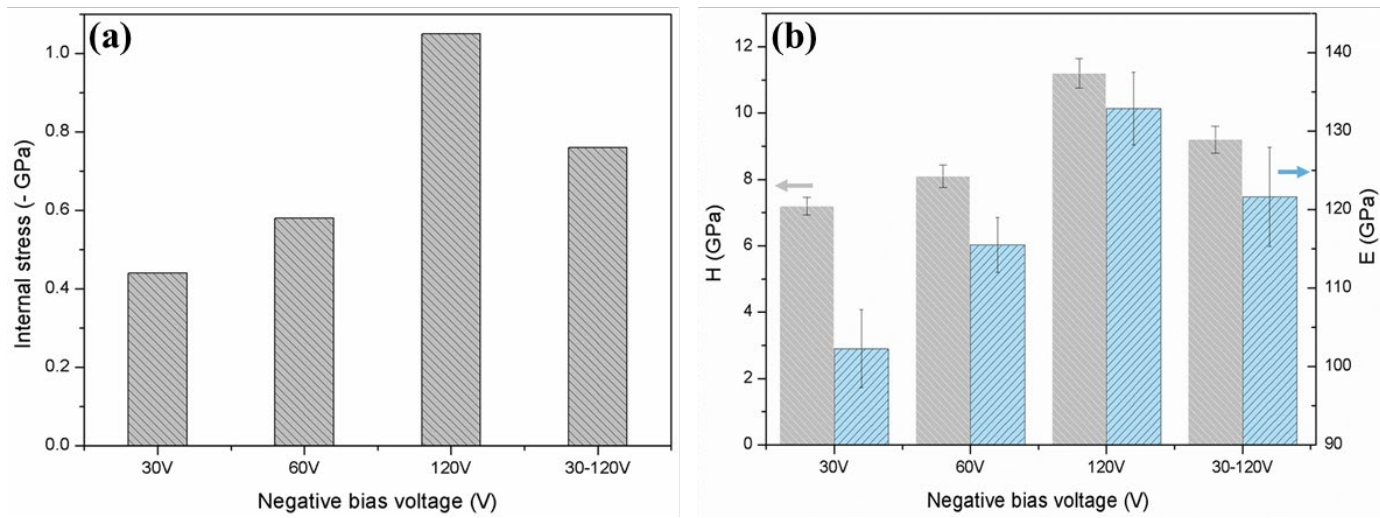

Figure 5. (a) Internal stress, (b) hardness and elastic modulus of the GLC films deposited at different negative bias voltage.

The hardness $(H)$ and elastic modulus $(E)$ of GLC films are shown in Figure 5b. It can be seen that both $H$ and $E$ increase with the increase of constant bias. A slight decrease of $H$ from average $11.2 \mathrm{GPa}$ to $9.3 \mathrm{GPa}$ is also observed for the bias-graded film, while the $E$ decreases from $133 \mathrm{GPa}$ to $122 \mathrm{GPa}$. Different reasons have been reported in previous studies to the high rigidity of GLC films with significant $\mathrm{sp}^{2}$-hybridized sites in the amorphous carbon matrix. Lacerda et al. [33] proposed that the formation of graphite-like a-C films with high stress and hardness could be attributed to the reduction of interplanar distance and the random distribution of $\mathrm{sp}^{2}$ cluster cross-linked by a small amount of $\mathrm{sp}^{3}$ sites. Baptista et al. [34] thought that the strong $\mathrm{sp}^{2} \sigma$-bonded three-dimensional carbon structure resulting from the distortion in the $\mathrm{sp}^{2}$ bond angle provided a rigidity network with high hardness for the $\mathrm{sp}^{2}$-rich 
amorphous carbon films. However, the $\pi$-bond in $\mathrm{sp}^{2}$ sites was thought conformably to be disadvantageous for the rigidity of the amorphous carbon structure, which could be inhibited by high internal stress or deep topological disorder [10.33.34]. According to the above Raman analysis, the increase of amorphization and disorder degree of the films can be deduced by the increasing of FWHM of G peak and movement of G peak position to lower wavelength [35], which signifies less free $\pi$-bond in $\mathrm{sp}^{2}$ sites with the increase of constant bias. Combination with the increased internal stress shown in Figure 5a, the improved $H$ and $E$ of GLC films with the increase of constant bias can be explained. In addition, the compact and uniform microstructure for CB3 deposited at $120 \mathrm{~V}$ is also an important factor for the highest hardness. Compared to CB3 film, the bias-graded film (BB1) possesses low $\mathrm{sp}^{3}$ content and internal stress resulting in a slight decrease of $H$ and $E$.

The adhesion strength between the film and substrate is an important parameter to evaluate the load bearing capacity and wear life of the films. The optical images of the scratch traces for the CB3 films deposited at the highest bias of $120 \mathrm{~V}$ and the bias-graded films (BB1) are given in Figure 6a. A clear difference can be observed in the fracture behaviour for the films deposited at constant bias and graded bias. There was an almost entire exfoliation on the CB3 film after a series of small delamination occurred in the early stage when the applied load increases to a critical value. For the bias-graded film, no apparent delamination appears until the end of the scratch trace, although some radial cracks on and around the scratch trace after a higher critical load, indicating the better adhesion strength than the films deposited at constant bias. This phenomenon can also be evidenced by the Rockwell indentation testing (Figure 6b), where some delamination can be found at the edge of the indentation impression for the CB3 sample, while the surface morphology is well-preserved for the bias-graded BB1 film. As mentioned in previous studies [25.36], such compositionally graded design can generate graded interface, which allows the mechanical properties of the interlayer to be changed gradually, avoiding stress concentration and discontinuities at the interface under loading. Thus the adhesion strength of the films can be significantly improved. 


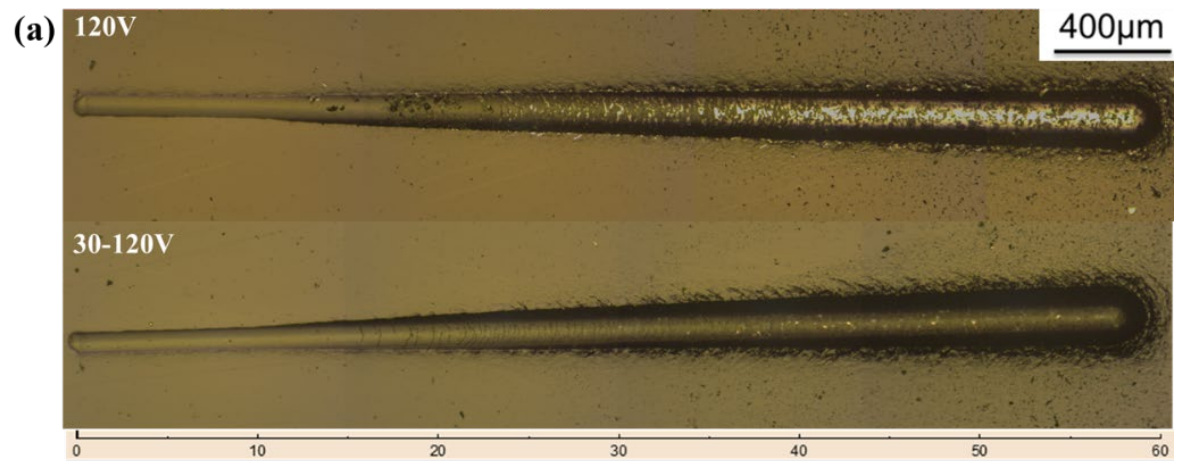

(b)
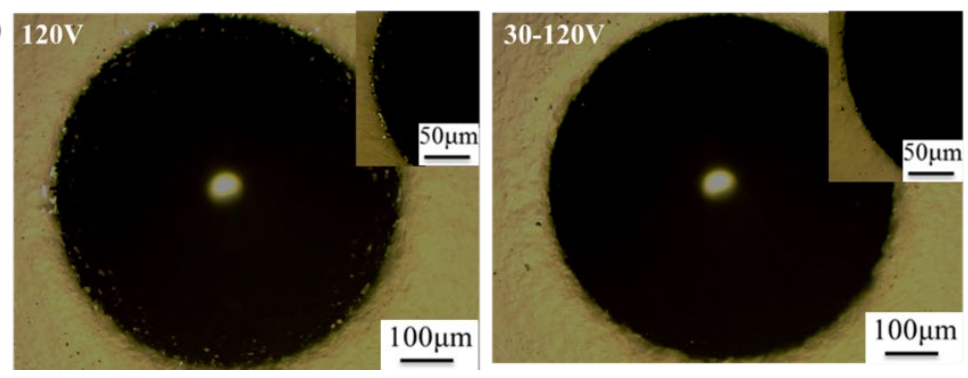

Figure 6. Optical images of (a) scratch traces, (b) Rockwell indentation impression for GLC film deposited at a constant bias of $120 \mathrm{~V}$ and bias-graded film.

\subsection{Fretting wear behaviors of GLC films}

\subsubsection{Friction and wear scars}

Fretting tests under different contact conditions such as displacement amplitudes, normal forces, and surface roughness can generate three different fretting regions, namely the gross slip regime (GSR), the partial slip regime (PSR), and the mixed slip regime (MSR) areas [12.27]. In the first case there is slip displacement across the whole contact, but in the second case there are parts of contact where no slip displacement occurs. The last case is the state in which both the partial and the gross slip regimes exist in one test [37]. The differences in the fretting wear region can be distinguished by the damage morphology of the contact region and fretting maps (tangential force-displacement amplitude-number of cycles). Figure 7 shows the typical fretting maps of GLC films deposited at the constant bias of $120 \mathrm{~V}$ and the bias-graded film, both of which present a closed parallelogram, indicating the GSR state always in the fretting contact region for the GLC films. 
(a)

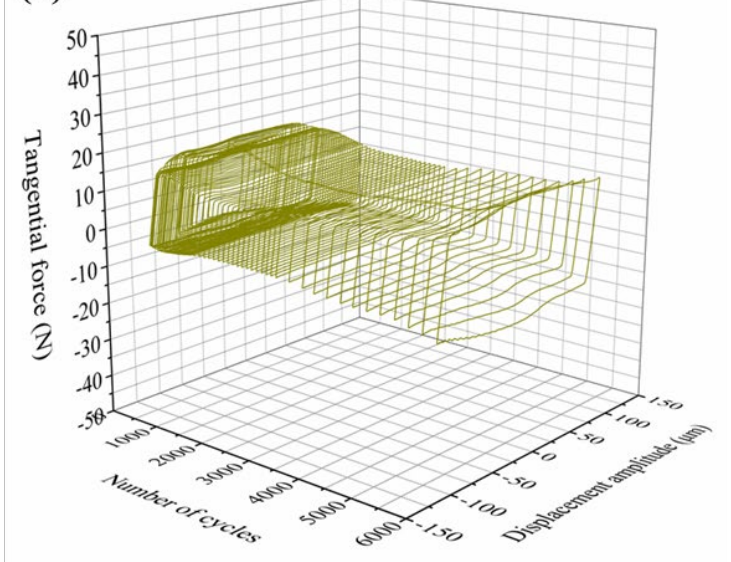

(b)

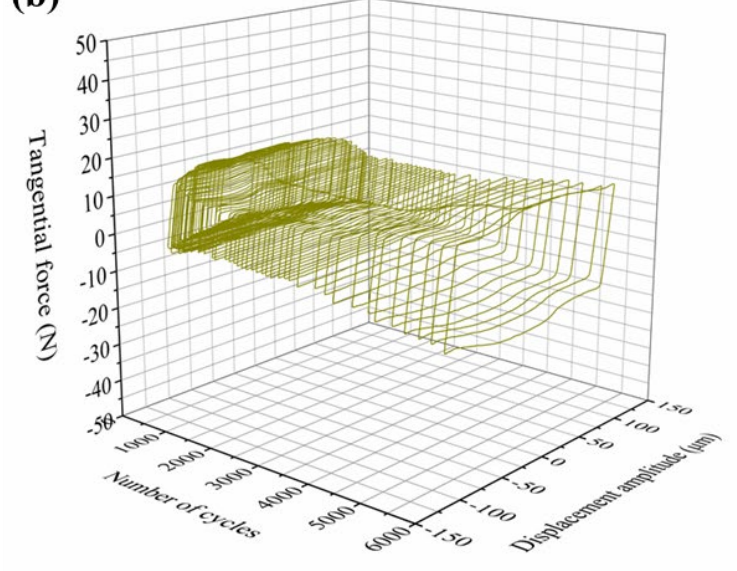

Figure 7. Typical fretting logs for testing on GLC films deposited at (a) the constant bias of $120 \mathrm{~V}$ and (b) bias-graded film.

The ratio of $\mathrm{Q}_{\max } / \mathrm{P}$ can be used to evaluate the friction coefficient $(\mathrm{CoF})$ for the case of a gross slip condition, in which the $\mathrm{Q}_{\max }$ is the maximum tangential force of a given cycle (shown in Figure 1b), and the $\mathrm{P}$ is the applied normal force. The evolution of $\mathrm{CoF}$ as a function of number of cycles for GLC films in both of ambient air and dry $\mathrm{N}_{2}$ atmosphere is shown in Figure 8a \&b. As can be observed, the CoF increases rapidly at the beginning of the test for about 150 cycles, which is referred to as the running-in period. Subsequently, the CoF decreases gradually to a steady value until the marked Point A, and then increases gradually to the marked Point B, followed by a dramatic increase to the value of about 0.9 , which is close to the CoF of the $316 \mathrm{~L}$ stainless steel substrate reported in our previous study [38]. Thus the marked Point B can be regarded as the fatigue life of the GLC films.

The steady values of $\mathrm{CoF}$ at Point $\mathrm{A}$ are shown in Figure 8c. In ambient air, the $\mathrm{CoF}$ decreases from 0.26 to 0.17 as the constant bias increases from $30 \mathrm{~V}$ to $120 \mathrm{~V}$, while the lowest $\mathrm{CoF}$ is about 0.15 for the bias-graded film. The fatigue life marked at Point $\mathrm{B}$ in ambient air is about 3250, 4750, 6750, and 8250 for the constant bias films of $\mathrm{CB} 1, \mathrm{CB} 2$ and $\mathrm{CB} 3$, and the bias-graded film (BB1), respectively, increasing with the constant bias (Figure 8d). A similar variation tendency of friction coefficient and fatigue life can be also observed for GLC films in dry $\mathrm{N}_{2}$ atmosphere, while the CoF is obviously lower and the fatigue life is longer than that in the ambient air. 

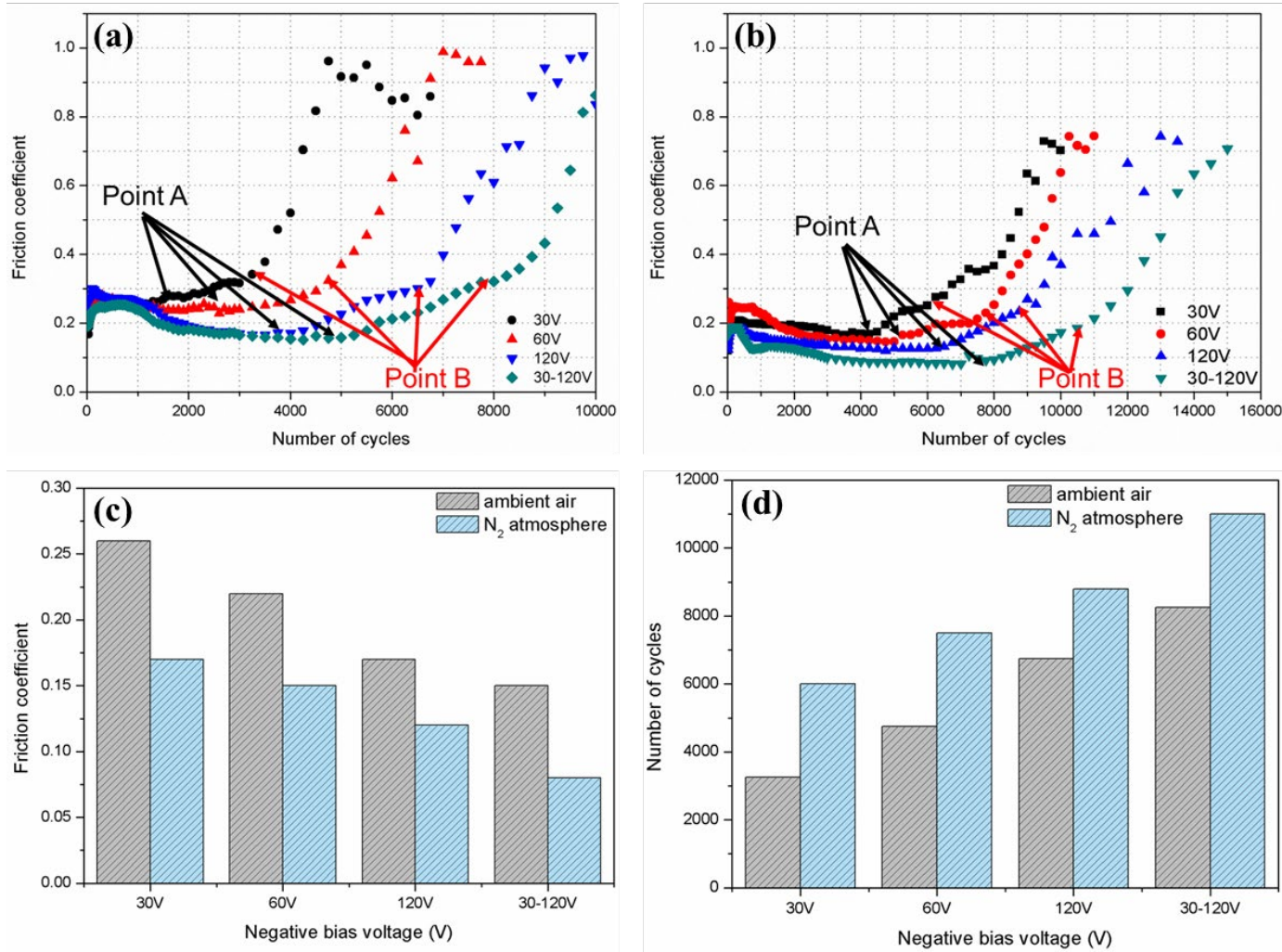

Figure 8. Evolution of friction coefficient as a function of the number of cycles for GLC films in (a) ambient air, (b) dry $\mathrm{N}_{2}$ atmosphere, (c) the stable friction coefficient in point $A$, (d) the fatigue life in point $B$ for both of ambient air and dry $\mathrm{N}_{2}$ atmosphere.

Figure 9 shows the SEM images of the wear scar for GLC films deposited at different negative bias voltage after 10000 fretting cycles. A scar width of around $0.5 \mathrm{~mm}$ is observed for all of the films, which is composed of severe wear areas in the middle and the mild flake-off in the edge of the wear track. The severe wear area almost covers the whole region of the wear track for the GLC films deposited at low negative bias (Figure 9a\&b), while the wear mark in the bias-graded film is lightest (Figure 9d). The EDX analysis indicates the $\mathrm{C}$ and Ti elements have almost been entirely removed and the Fe element is exposed in the severe wear area, which means that the GLC film and Ti adhesive layer have been destroyed completely and that the $316 \mathrm{~L}$ stainless steel substrate is in contact with the mating ball in the middle of the wear track after 10000 cycles. This result is coincident with the CoF of about 0.9 at the end of test shown in Figure 8a. Besides, the presence of the oxygen element in the severe wear area proves the occurring of oxidation when the substrate is exposed during the tests. In the edge of the wear track, obvious flake-off developed by large cracks can be observed on the surface. Furthermore, the specific wear rate of the GLC films is difficult to calculate due to the occurrence of wear on the substrate. 

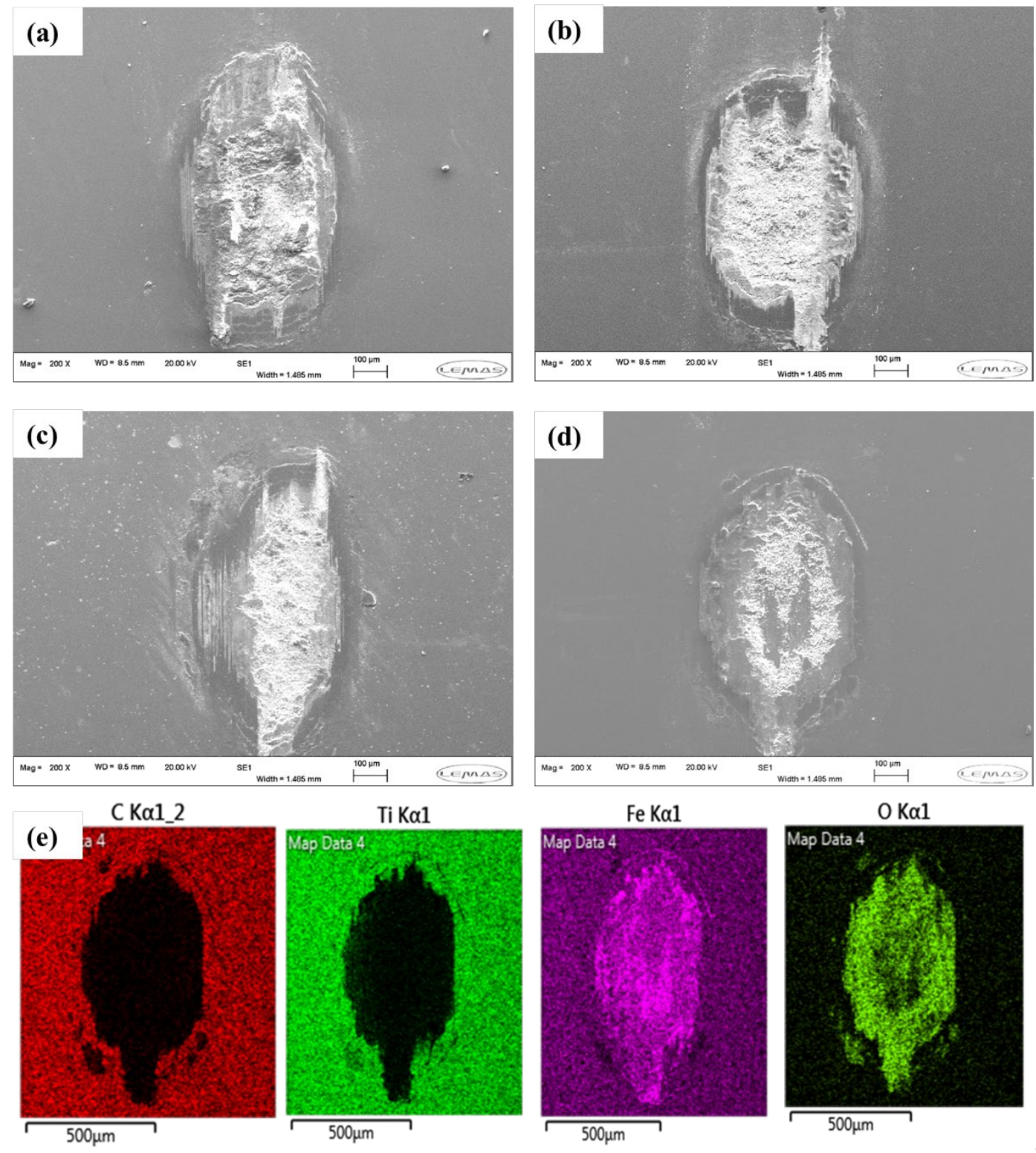

Figure 9. SEM images of fretting wear scar after 10000 cycles in ambient air condition for GLC films deposited at constant bias voltage (a) $30 \mathrm{~V}$, (b) $60 \mathrm{~V}$, (c) $120 \mathrm{~V}$, and (d) bias-graded film, (e) EDX mapping of wear scar for the bias-graded film.

\subsubsection{Fretting wear mechanism}

To investigate the fretting wear mechanism of GLC films, the fretting wear tests for the bias-graded film with different cycles in ambient air condition were conducted. Figure 10 shows the SEM images and the surface profile of the wear tracks after 3000, 6000 and 8000 fretting cycles, and the corresponding EDX maps are listed in Figure 11. At 3000 fretting cycles, the CoF in Figure 8a is close to the steady value at Point A. As can be seen from Figure 10a, the wear track is smooth and the film is still intact, although there is some shallow scratch on the wear track, indicating the occurrence of mild abrasive wear. The EDX maps in Figure 11a also evidenced the 
complete surface structure in this stage. After 6000 fretting cycles, the CoF in Figure 8a located in the gradually increased stage between Point A and B. More obvious abrasive wear can be deduced by the surface profile and morphology. Large delamination of the GLC films can be observed in SEM image and EDX mapping, especially at the edge of the wear track (Figure 10b and Figure 11b). However, the maximum wear depth is close to $0.5 \mu \mathrm{m}$, lower than the thickness of the whole film. When the fretting cycles is up to 8000 at around Point B, the GLC film on the wear surface was almost removed completely, and even large exfoliation can be observed on the wear track (Figure 10c). The surface profile shows the maximum wear depth is close to $1.5 \mu \mathrm{m}$, larger than the film thickness, indicating the exposure of the substrate and the occurrence of adhesive wear, which is also consistent with the EDX results (Figure 11c).
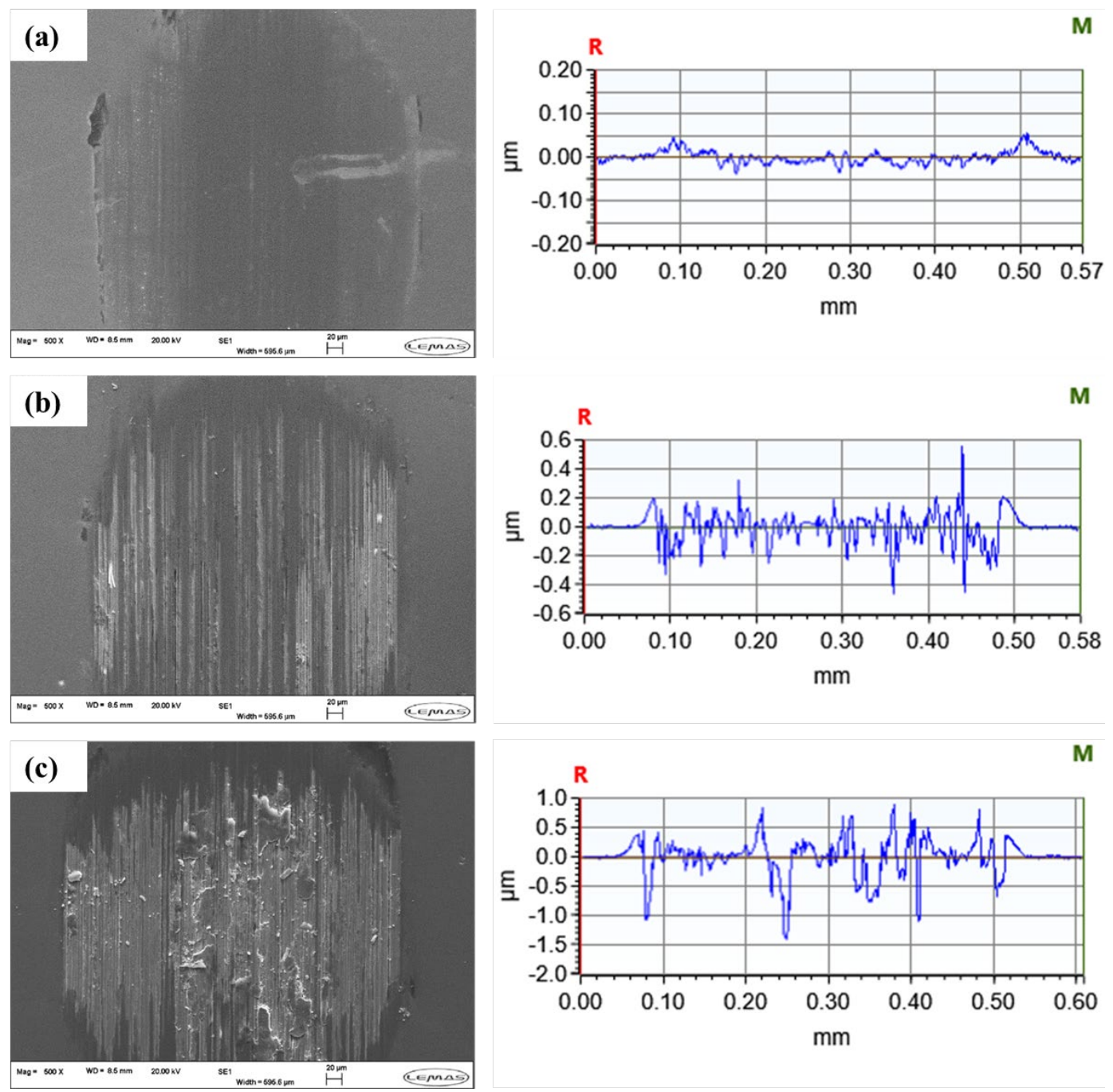

Figure 10. SEM images of wear scar and the corresponding surface profile for the bias-graded GLC film after (a) 3000, (b) 6000, (c) 8000 fretting cycles in ambient air condition. 

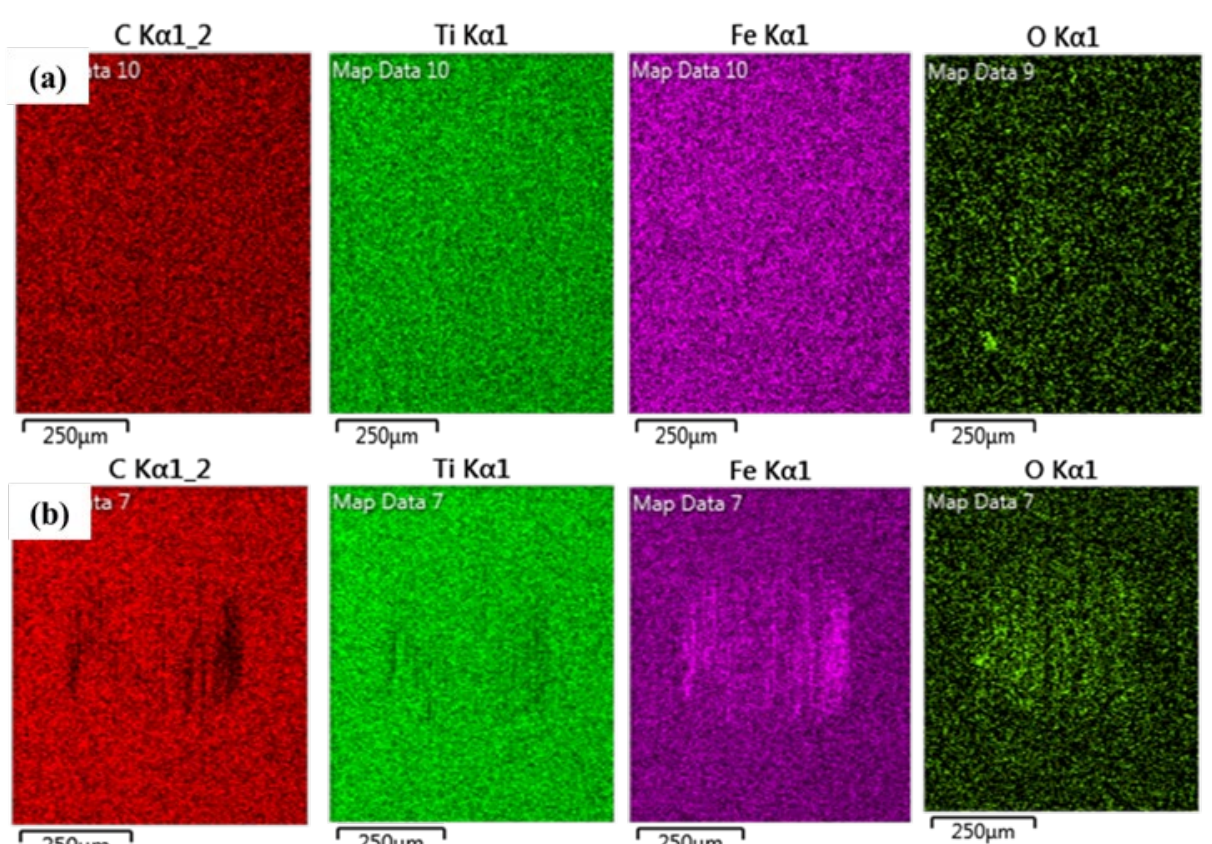

$\mathrm{Ti} K \alpha 1$
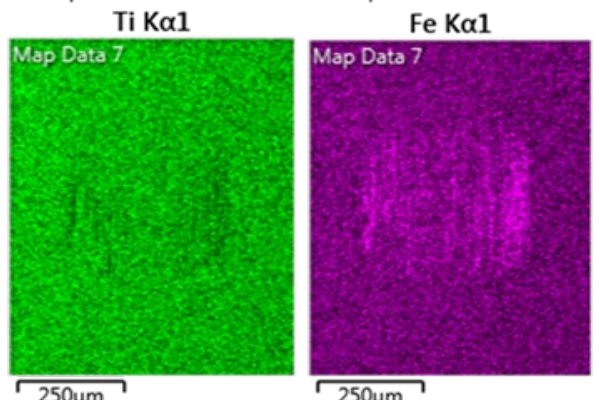

$250 \mu \mathrm{m}$
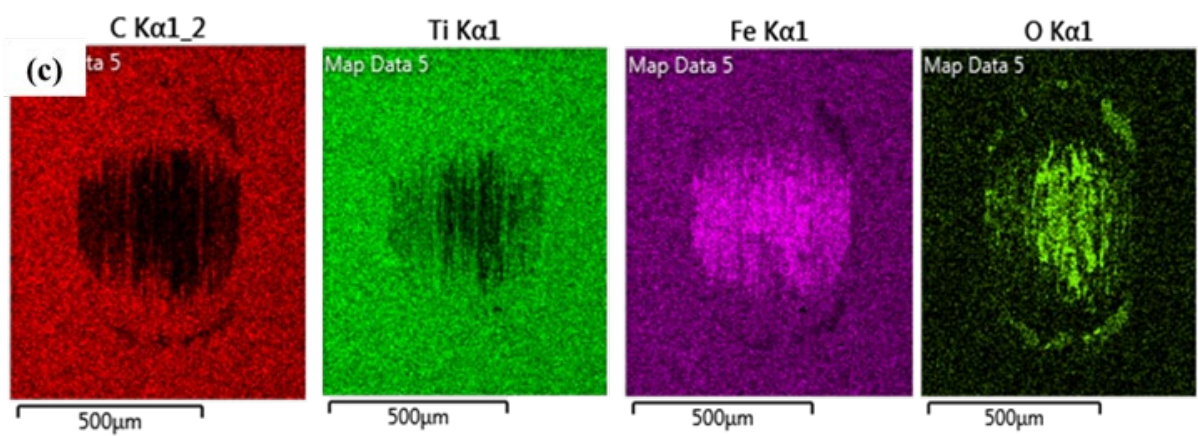

Figure 11: The EDX mapping of wear scar for the bias-graded film at different fretting cycles (a) 3000, (b) 6000, (c) 8000 .

Based on the above analysis of the friction curves and observation of wear scars at different fretting cycles, the fretting wear of GLC films can be divided into three different stages (Figure 12). In the first stage, the fretting wear is mainly occurred on the surface of the GLC film, and there could be a slight decrease of the film thickness due to the material loss of GLC film causing by abrasive wear. The gradually decreased $\mathrm{CoF}$ may be related to the transformation of phase structure in amorphous matrix from $\mathrm{sp}^{3}$ to $\mathrm{sp}^{2}$ carbon atoms induced by stress under fretting contact, and the formation of the lubricious graphite-like films between the film surface and the mating ball [39]. In addition, micro-cracks may be generated in this stage due to stress concentration induced by small abrasive particles. As the increase of fretting cycles to Point A, the micro-cracks would further develop and coalesce each other, leading to the flake-off of some small pieces of GLC films in the second stage. As described above, the maximum wear depth in Figure 10b is smaller than the film thickness, thus 
it can be deduced the exposed area resulting from the delamination of GLC film may be the Ti-C transition layer. The slowly increased $\mathrm{CoF}$ in the second stage may be attributed to the gradually decreased $\mathrm{C}$ and increased $\mathrm{Ti}$ content as the increase of wear depth. Besides, the gradually increased exfoliation area of GLC film is also an important factor to the increased $\mathrm{CoF}$ in this stage. When the number of fretting cycles reaches to Point B, the surface layer of GLC films was destroyed completely and the substrate was exposed, leading to the dramatic increase of $\mathrm{CoF}$ to the value of substrate.

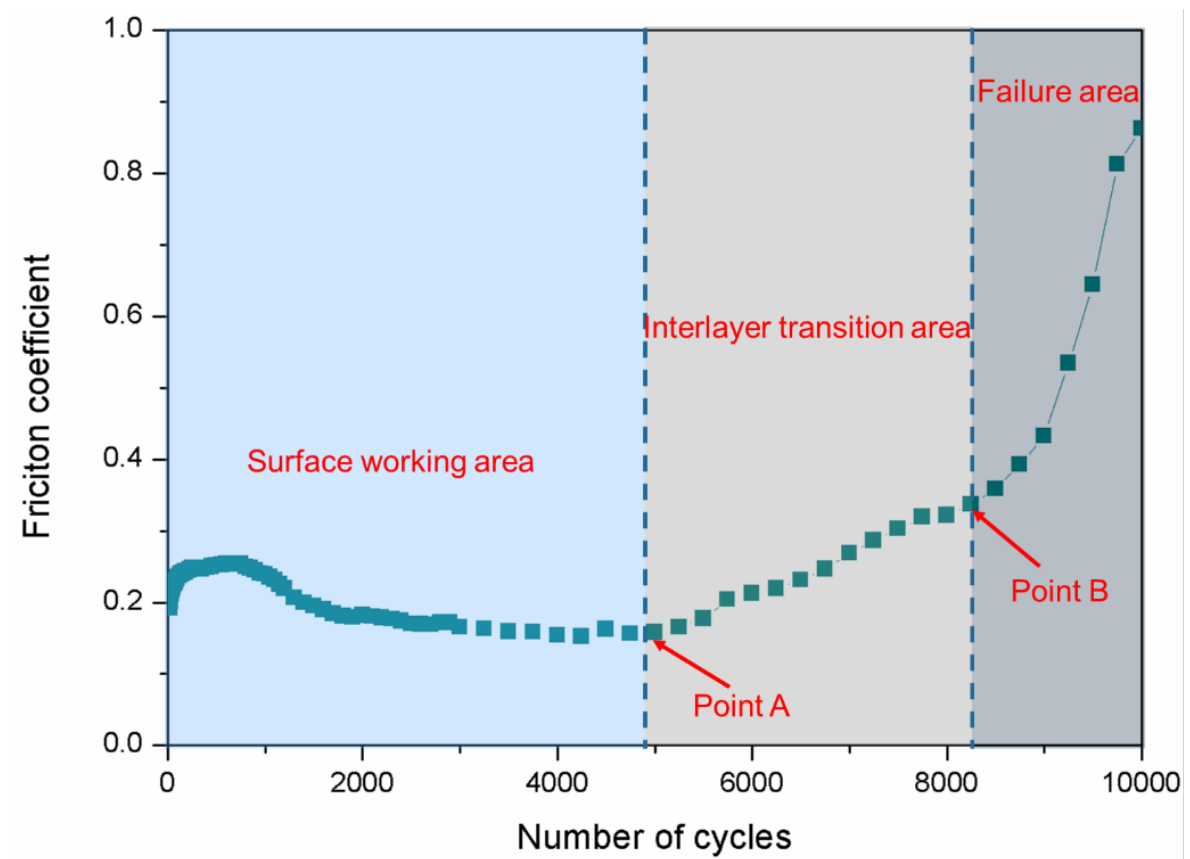

Figure 12. The film failure process illustrated by the evolution of friction coefficient of bias-graded film at Figure 8a.

As reported in previous studies, the friction coefficient of amorphous carbon films is not only relevant with the relative content of $\mathrm{sp}^{2}$ sites [6.29], but also related to the mechanical properties of the as-deposited films [11.38.40]. As seen from Figure 8c, the stable $\mathrm{CoF}$ value decreases with the increase of constant bias regardless of the decreased $\mathrm{sp}^{2}$ content evidenced by Raman and XPS analysis (Figure 3\&4), which may be closely linked with the gradually increased $H$ and $E$. From the surface profile in Figure 10, there is almost no plastic deformation on the substrate during the fretting tests, thus the intrinsic mechanical properties of the films are responsible for the initial contact. Among the GLC films deposited at constant bias voltage, the CB3 film deposited at the highest bias of $120 \mathrm{~V}$ shows the highest $E$ of about $133 \mathrm{GPa}$, which is more resistant to initial contact stress, producing a smaller contact area at the applied normal load, and reducing the friction resistance. Besides, the increase of compactness in the internal structure and the decrease of surface roughness are also 
responsible for the decreased $\mathrm{CoF}$ with the increase of constant bias. The lowest CoF of bias-graded film may be attributed to the combined properties with high hardness, low surface roughness and high $\mathrm{sp}^{2}$ cluster in the structure.

Furthermore, the prolonged fatigue life of GLC films deposited at high constant bias can also be ascribed to the enhanced intrinsic hardness and reduced flaws in the structure, which can increase the load-bearing capacity of GLC films and postpone the formation and propagation of micro-cracks on the surface of the films. Compared to the CB3 film deposited at constant bias of $120 \mathrm{~V}$, the low internal stress and high adhesive strength are the main advantages for the longer fatigue life of bias-graded film. Besides, the inhomogeneity effect of materials also should be favourable to the best service life of bias-graded film, which has been used to significantly improve the fracture toughness of thin film components by affecting the growth of cracks [41.42]. During the fretting wear, the different elastoplasticities of the hard film and the soft substrate can cause severe stress concentration, which can drive the nucleation of micro-cracks at the interface and propagate upward to the surface of the film. According to the inhomogeneity effect, the interface between the different graded interlayers could drop the growth rate of cracks precipitously, which will ultimately prolong the fatigue life of bias-graded film.

In general, the test environment also plays an important role in the friction and wear performance of amorphous carbon films [43-45]. Johnson et al. [46] has proved that an adsorbed film with thickness of several angstroms can be formed on surface of amorphous carbon films due to the interaction between the films and the surrounding species like oxygen, water molecules, hydrocarbons, etc., which may prevent the formation of the transfer film during the fretting process [7.47]. Compared to the ambient air, the absence of oxygen and water molecules in the dry $\mathrm{N}_{2}$ atmosphere may be beneficial to the formation of the transfer film, leading to lower friction coefficient. In addition, a viscous drag and capillary forces may be initiated in the contact surface when the water molecules were adsorbed in ambient air [48], which could cause a high adhesive force and hence higher friction coefficient than in the dry $\mathrm{N}_{2}$ atmosphere. Furthermore, the presence of oxygen in ambient air can lead to the oxidation of the substrate evidenced by the EDX in Figure 9, which should be also an important reason for the higher friction coefficient and lower fatigue life than those in dry $\mathrm{N}_{2}$ atmosphere.

\section{Conclusion}


The bias-graded deposition was used to prepare the GLC film by closed-filed unbalanced magnetron sputtering. The microstructure, mechanical, fretting wear and failure behaviors was investigated systematically by comparing with the films deposited at constant bias.

(1) The $\mathrm{sp}^{2}$ content and surface roughness decreased with the increase of constant bias, resulting in the enhanced compactness and surface hardness, which predicted the comparable surface hardness and superior adhesive strength for the bias-graded film due to the gradient variation of $\mathrm{sp}^{2} / \mathrm{sp}^{3}$ ratio.

(2) The bias-graded film has the lowest $\mathrm{CoF}$ and longest fatigue life during the fretting wear tests, while the fretting wear properties show an improved tendency with the increase of constant bias. The optimal fretting wear properties of the bias-graded film may be attributed to the combined properties of good adhesive strength, high hardness, low surface roughness and high $\mathrm{sp}^{2}$ cluster in the structure.

(3) Three different stages were proposed to explain the fretting wear process of GLC film. In the surface working area, the gradually decreased CoF is mainly attributed to the formation of graphite-like transfer film and the phase transformation. The delamination of GLC films in the transition area caused by the formation and propagation of cracks, lead to the gradually increased Cof. Finally, the substrate was exposed and the $\mathrm{CoF}$ increased dramatically.

\section{Acknowledgment}

The authors gratefully acknowledge the financial support from the NSFC (\#11472080), the NSF of Jiangsu Province (\#BK20141336), the Fundamental Research Funds for the Central Universities, the financial support from the program of China Scholarships Council (No. 201706090126), and the postgraduate training innovation project of Jiangsu Province (KYLX16_0198).

\section{References:}

[1]T. Watabe, A. Amanov, R. Tsuboi, S. Sasaki, Friction and Fretting Wear Characteristics of Different Diamond-Like Carbon Coatings Against Alumina in Water-Lubricated Fretting Conditions, J. NANOSCI. NANOTECHNO., 13(2013) 8167-8175.

[2]A. Amanov, T. Watabe, R. Tsuboi, S. Sasaki, Fretting wear and fracture behaviors of Cr-doped and non-doped DLC films deposited on $\mathrm{Ti}-6 \mathrm{al}-4 \mathrm{~V}$ alloy by unbalanced magnetron sputtering, TRIBOL. INT., 62(2013) 49-57.

[3]F. Yıldız, A.F. Yetim, A. Alsaran, A. Çelik, İ. Kaymaz, Fretting fatigue properties of plasma nitrided AISI 316L stainless steel: Experiments and finite element analysis, TRIBOL. INT., 44(2011) 1979-1986. 
[4]L. Gil, S. Brühl, L. Jiménez, O. Leon, R. Guevara, M.H. Staia, Corrosion performance of the plasma nitrided 316L stainless steel, Surface and Coatings Technology, 201(2006) 4424-4429.

[5]K. Bewilogua, D. Hofmann, History of diamond-like carbon films - From first experiments to worldwide applications, Surface and Coatings Technology, 242(2014) 214-225.

[6]Y. Wang, Y. Ye, H. Li, L. Ji, J. Chen, H. Zhou, A magnetron sputtering technique to prepare a-C:H films: Effect of substrate bias, APPL. SURF. SCI., 257(2011) 1990-1995.

[7]P. Navaneethakrishnan, S. Ganesh Sundara Raman, S.D. Pathak, R. Gnanamoorthy, N. Ravi, Fretting wear studies on diamond-like carbon coated $\mathrm{Ti}-6 \mathrm{Al}-4 \mathrm{~V}$, Surface and Coatings Technology, 203(2009) 1205-1212.

[8]A. Grill, Diamond-like carbon: state of the art, DIAM. RELAT. MATER., 8(1999) 428-434.

[9]D. Du, D. Liu, Z. Ye, X. Zhang, F. Li, Z. Zhou, L. Yu, Fretting wear and fretting fatigue behaviors of diamond-like carbon and graphite-like carbon films deposited on Ti-6Al-4V alloy, APPL. SURF. SCI., 313(2014) 462-469.

[10]Y. Wang, J. Li, L. Shan, J. Chen, Q. Xue, Tribological performances of the graphite-like carbon films deposited with different target powers in ambient air and distilled water, TRIBOL. INT., 73(2014) 17-24.

[11]D. Dong, B. Jiang, H. Li, Y. Du, C. Yang, Effect of graphite target power density on tribological properties of graphite-like carbon films, APPL. SURF. SCI., 439(2018) 900-909.

[12]H.H. Ding, V. Fridrici, J. Geringer, J. Fontaine, P. Kapsa, Influence of diamond-like carbon coatings and roughness on fretting behaviors of $\mathrm{Ti}-6 \mathrm{Al}-4 \mathrm{~V}$ for neck adapter - femoral stem contact, WEAR, 406-407(2018) 53-67.

[13]A.L. Mohd Tobi, P.H. Shipway, S.B. Leen, Gross slip fretting wear performance of a layered thin W-DLC coating: Damage mechanisms and life modelling, WEAR, 271(2011) 1572-1584.

[14]M. Kalin, J. Vižintin, The tribological performance of DLC coatings under oil-lubricated fretting conditions, TRIBOL. INT., 39(2006) 1060-1067.

[15]R.L. Li, J.P. Tu, C.F. Hong, D.G. Liu, D.H. Zhou, H.L. Sun, Microstructure and tribological properties of Ti-contained amorphous carbon film deposited by DC magnetron sputtering, J. APPL. PHYS., 106(2009) 123508.

[16]X. Sui, J. Liu, S. Zhang, J. Yang, J. Hao, Microstructure, mechanical and tribological characterization of CrN/DLC/Cr-DLC multilayer coating with improved adhesive wear resistance, APPL. SURF. SCI., 439(2018) 24-32.

[17]Y. Wang, J. Pu, J. Wang, J. Li, J. Chen, Q. Xue, Interlayer design for the graphite-like carbon film with high load-bearing capacity under sliding-friction condition in water, APPL. SURF. SCI., 311(2014) 816-824.

[18]F. Li, S. Zhang, J. Kong, Y. Zhang, W. Zhang, Multilayer DLC coatings via alternating bias during magnetron sputtering, THIN SOLID FILMS, 519(2011) 4910-4916.

[19]L. Ward, F. Junge, A. Lampka, M. Dobbertin, C. Mewes, M. Wienecke, The Effect of Bias Voltage and Gas Pressure on the Structure, Adhesion and Wear Behavior of Diamond Like Carbon (DLC) Coatings With Si Interlayers, COATINGS, 4(2014) 214-230.

[20]Y. Wang, L. Wang, G. Zhang, S.C. Wang, R.J.K. Wood, Q. Xue, Effect of bias voltage on microstructure and properties of Ti-doped graphite-like carbon films synthesized by magnetron sputtering, Surface and Coatings Technology, 205(2010) 793-800.

[21]P. Wang, X. Wang, Y. Chen, G. Zhang, W. Liu, J. Zhang, The effect of applied negative bias voltage on the structure of Ti-doped a-C:H films deposited by FCVA, APPL. SURF. SCI., 
253(2007) 3722-3726.

[22]C. Ziebert, C. Bauer, M. Stüber, S. Ulrich, H. Holleck, Characterisation of the interface region in stepwise bias-graded layers of DLC films by a high-resolution depth profiling method, THIN SOLID FILMS, 482(2005) 63-68.

[23]C. Bauer, H. Leiste, M. Stuber, S. Ulrich, H. Holleck, Mechanical properties and performance of magnetron-sputtered graded diamond-like carbon films with and without metal additions (vol 11, pg 1139, 2002), DIAM. RELAT. MATER., 11(2002) 1713.

[24]S. Zhang, X.L. Bui, Y. Fu, D.L. Butler, H. Du, Bias-graded deposition of diamond-like carbon for tribological applications, DIAM. RELAT. MATER., 13(2004) 867-871.

[25]J.B. Cai, X.L. Wang, W.Q. Bai, X.Y. Zhao, T.Q. Wang, J.P. Tu, Bias-graded deposition and tribological properties of Ti-contained a-C gradient composite film on Ti6Al4V alloy, APPL. SURF. SCI., 279(2013) 450-457.

[26]G.M. Pharr, W.C. Oliver, Measurement of Thin Film Mechanical Properties Using Nanoindentation, MRS BULL., 17(1992) 28-33.

[27]K.J. Kubiak, T.W. Liskiewicz, T.G. Mathia, Surface morphology in engineering applications: Influence of roughness on sliding and wear in dry fretting, TRIBOL. INT., 44(2011) 1427-1432.

[28]T. Liskiewicz, K. Kubiak, T. Comyn, Nano-indentation mapping of fretting-induced surface layers, TRIBOL. INT., 108(2017) 186-193.

[29]M. Huang, X. Zhang, P. Ke, A. Wang, Graphite-like carbon films by high power impulse magnetron sputtering, APPL. SURF. SCI., 283(2013) 321-326.

[30]Y. Lifshitz, S.R. Kasi, J.W. Rabalais, W. Eckstein, Subplantation model for film growth from hyperthermal species, Physical review. B, Condensed matter, 41(1990) 10468-10480.

[31]H.Y. Dai, X.R. Cheng, C.F. Wang, Y.C. Xue, Z.P. Chen, Structural, optical and electrical properties of amorphous carbon films deposited by pulsed unbalanced magnetron sputtering, OPTIK, 126(2015) 861-864.

[32]S. Sun, Y. Wang, X. Lu, X. Lu, C. Mao, Z. Zeng, Q. Xue, Achieving excellent tribological performance of a-C: WC film by controlling sub-nano-structure, TRIBOL. INT., 128(2018) $65-74$.

[33]R.G. Lacerda, P. Hammer, C.M. Lepienski, F. Alvarez, F.C. Marques, Hard graphitic-like amorphous carbon films with high stress and local microscopic density, Journal of Vacuum Science \& Technology A: Vacuum, Surfaces, and Films, 19(2001) 971-975.

[34]D.L. Baptista, F.C. Zawislak, Hard and sp2-rich amorphous carbon structure formed by ion beam irradiation of fullerene, a-C and polymeric a-C:H films, DIAM. RELAT. MATER., 13(2004) $1791-1801$

[35]A.C. Ferrari, J. Robertson, Interpretation of Raman spectra of disordered and amorphous carbon, PHYS. REV. B, 61(2000) 14095-14107.

[36]D. Galvan, Y.T. Pei, J.T.M. De Hosson, TEM characterization of a Cr/Ti/TiC graded interlayer for magnetron-sputtered TiC/a-C:H nanocomposite coatings, ACTA MATER., 53(2005) 3925-3934.

[37]A. Lenart, P. Pawlus, A. Dzierwa, J. Sęp, K. Dudek, The effect of surface topography on dry fretting in the gross slip regime, ARCH CIV MECH ENG, 17(2017) 894-904.

[38]X. Shi, T.W. Liskiewicz, B.D. Beake, J. Chen, C. Wang, Tribological performance of graphite-like carbon films with varied thickness, TRIBOL. INT., (2019).

[39]S.K. Field, M. Jarratt, D.G. Teer, Tribological properties of graphite-like and diamond-like carbon coatings, TRIBOL. INT., 37(2004) 949-956. 
[40]Y. Wang, H. Li, L. Ji, F. Zhao, Q. Kong, Y. Wang, X. Liu, W. Quan, H. Zhou, J. Chen, Microstructure, mechanical and tribological properties of graphite-like amorphous carbon films prepared by unbalanced magnetron sputtering, Surface and Coatings Technology, 205(2011) 3058-3065.

[41]D. Kozic, H.P. Gänser, R. Brunner, D. Kiener, T. Antretter, O. Kolednik, Crack arrest in thin metallic film stacks due to material- and residual stress inhomogeneities, THIN SOLID FILMS, 668(2018) 14-22.

[42]N.K. Simha, F.D. Fischer, O. Kolednik, C.R. Chen, Inhomogeneity effects on the crack driving force in elastic and elastic-plastic materials, J. MECH. PHYS. SOLIDS, 51(2003) 209-240.

[43]J. Andersson, R.A. Erck, A. Erdemir, V. Teknisk-naturvetenskapliga, U. Uppsala, F.T. Institutionen, S. Tekniska, Frictional behavior of diamondlike carbon films in vacuum and under varying water vapor pressure, SURF. COAT. TECH., 163-164(2003) 535-540.

[44]A. Erdemir, O.L. Eryilmaz, I.B. Nilufer, G.R. Fenske, Synthesis of superlow-friction carbon films from highly hydrogenated methane plasmas, SURF. COAT. TECH., 133(2000) 448-454.

[45]H. Ronkainen, S. Varjus, K. Holmberg, Tribological performance of different DLC coatings in water-lubricated conditions, WEAR, 249(2001) 267-271.

[46]J.A. Johnson, J.B. Woodford, A. Erdemir, G.R. Fenske, Near-surface characterization of amorphous carbon films by neutron reflectivity, APPL. PHYS. LETT., 83(2003) 452-454.

[47]P. Navaneethakrishnan, S. Ganesh Sundara Raman, R. Gnanamoorthy, N. Ravi, Relative performance of hydrogenated, argon-incorporated and nitrogen-incorporated diamond-like carbon coated $\mathrm{Ti}-6 \mathrm{Al}-4 \mathrm{~V}$ samples under fretting wear loading, THIN SOLID FILMS, 517(2009) 4365-4371.

[48]A. Erdemir, The role of hydrogen in tribological properties of diamond-like carbon films, SURF. COAT. TECH., 146(2001) 292-297. 